Revista de Ensino em Artes, Moda e Design

Dossiê 3

Novas perspectivas de aprendizagem

\title{
UMA PROPOSTA DA MODA COMO CONHECIMENTO PARA A FORMAÇÃO DO OLHAR DO ESTUDANTE DE MEDICINA NO AGRESTE PERNAMBUCANO.
}

The fashion as a knowledge for the training of the looks student's at medicine.

Maria Teresa Lopes ${ }^{1}$ 


\title{
Resumo
}

Este artigo consiste na apresentação de como se deu um projeto interdisciplinar de intervenção educacional (2015 a 2018), entre os campos das visualidades e da saúde, tendo como "Território de Aprendizagem" os curso de design e medicina do Campos Acadêmico do Agreste - CAA - da Universidade Federal de Pernambuco - UFPE. Tendo como base o pressuposto de dar início a um processo de formação do olhar para os futuros médicos da região Agreste do estado de Pernambuco, a partir da apresentação e discussão de modelos, atividades e resultados projetuais desenvolvidos pensando em aproximar o design e a moda e suas dinâmicas de poder, dentição e espaços de aprendizagem dos alunos ainda do primeiro ano de medicina.

Palavras-Chave: Formação do Olhar; Design; Medicina.

\begin{abstract}
This article consists of the presentation of an interdisciplinary project of educational intervention (2015 to 2018), between the fields of visual and health, having as the "Territory of Learning" the courses of design and medicine of Campos Acadêmic of Agreste - CAA - Federal University of Pernambuco - UFPE. Based on the assumption of initiating a process of Training of the Eyes for the future physicians of the Agreste region of the state of Pernambuco, from the presentation and discussion of models, activities and design results developed with the intention of approaching design and fashion and their dynamics of power, dentition and learning spaces of the students still of the first year of medicine.
\end{abstract}

Keywords: Training of the eyes; Design; Medicine. 


\section{INTRODUÇÃO}

Este artigo discute a formação de estudantes do campo da saúde, partindo dos campos do design e da moda (visualidades) como sistemas argumentativos e estruturantes para a Formação do Olhar desses discentes, em particular os que cursam medicina no Núcleo de Ciências da Vida - NCV, por meio do Laboratório de Sensibilidades - LabSensi -, Coordenado pelas professoras Eline Gomes, Carolina Paz, Heloísa Germany e Rafaela Lira, devido a uma parceria acadêmica com o LabFOL - o Laboratório de Formação do Olhar do Núcleo de Design e Comunicação, coordenado pela professora Teresa Lopes.

A parceria entre esses dois espaços científicos e de formação para os alunos da UFPE do Campus Acadêmico do Agreste, pode ser melhor compreendida por meio da figura abaixo:

Figura 01: Proposta de formação e produção de conhecimento por Território de Aprendizagem.

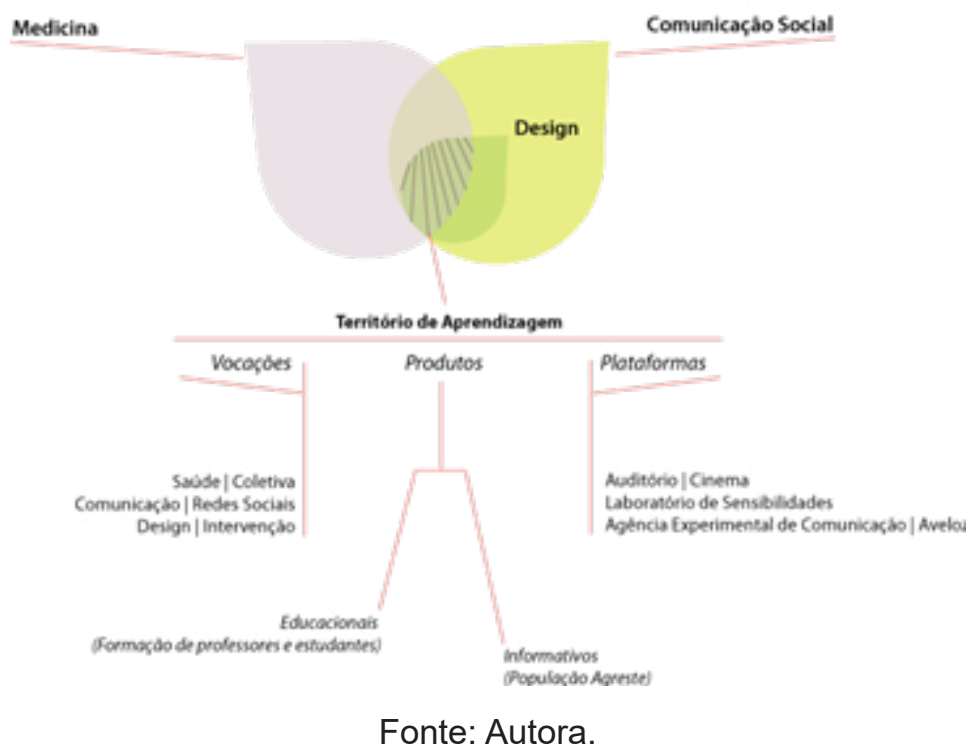

Assim, depois de delimitado o Território de Aprendizagem foi possível organizar-se um processo de pesquisação, cujo objetivo geral foi o compartilhamento de saberes, práticas, ações e equipamentos institucionais, para o desenvolvimento humano e social da região Agreste, por meio de conteúdos de Formação do olhar, Design/educação e Arte/educação, Moda/Educação visto essa ser a natureza epistemológica do LabFol, a partir dos seguintes objetivos específicos:

1. Discutir no âmbito acadêmico e comunitário, sistemas de significação comuns entre os campos das visualidades e da saúde;

2. Organizar os conteúdos de design, moda e arte/educação para a formação do olhar dos agentes sociais da comunidade universitária do campo da saúde;

3. Produzir conteúdos e práticas formativas para alunos, professores, servidores (de ambos os núcleos) e comunidades da região;

4. Promover ações formativas com base na natureza científica e significante de cada espaço (LabSense e LabFol), por meio da tríade universitária: ensino, pesquisa e extensão;

Para continuarmos é interessante entender o que é compreendido como Formação do Olhar, para tanto deve-se seguir o entendimento da autora que diz: 
Formação do olhar é um processo de ensino e aprendizagem, que nesse caso depende da figura de um mediador discursivo (no caso um professor), que ocorre por meio do uso e do agenciamento de imagens. Imagens estas que são entendidas como manifestação e materialização em aparência de um discurso visual. Essa formação prevê etapas de leitura, análise e crítica do corpo de significação em que essas imagens se estruturam, que assim se organizam para articular a emancipação da pessoa que faça parte desse processo. (LOPES, p.469, 2014)

O conceito acima foi trabalhado para o entendimento de que os alunos de medicina, já antes de ingressarem no curso, estão sujeitos a uma particularidade de imagens e paisagens visuais, notadamente as que são divulgadas pela mídia, destacando-se as que são significantes do seu campo de aprendizagem, que colaboram para o entendimento de que, de forma inconsciente eles completam as lacunas de ansiedade profissional emulando e absorvendo um certo Discurso Visual do que seria um profissional de saúde, tudo isso por meio desse universo imagético descrito.

Assim, pode-se seguir entendendo que essas imagens assumem uma condição que é semiótica, e que aqui é descrita como uma manifestação e/ou uma materialização do que esses alunos tem como expectativa da sua atuação com futuros médicos e que por ser uma emulação imagética, entronizada ao seu ethus, precisa ser amplamente discutida para haja a desmitificação de alguns valores, notadamente os relacionados a poder, autocontrole e infalibilidade, principalmente por que a realidade de estudo deles será a região Agreste, que do ponto de vista da sua realidade, está visual, geopolítica e culturalmente muito distante do que se é difundido em Grey's Anatomy ou Doctor House.

Para ser definido o conceito de Discurso Visual tem se que:

\begin{abstract}
... tomando-se Foucault como referência, começa a ser definido como todos os demais discursos, ou seja, como um ato humano para a sistematização de um organismo de significados, que para existir ancora-se em um campo de poder simbólico disciplinar e sobre os sombreamentos prováveis e possíveis com os demais campos. Esse tipo de discurso se caracteriza ainda, assim como os não-visuais, por envolver-se em uma vontade de verdade que é ideológica e às vezes política, e revela, como argumento de diferenciação dos não-visuais, a condição de que a sua manifestação é aparente e por decantação de ideologia em aparência. (LOPES, p.57, 2014)
\end{abstract}

A contribuição do LabFOL consistiu no assessoramento em estudos de base qualitativa e de práticas de análises discursivas, que tomou como objetos de estudo os fenômenos sócio-culturais que os conhecimentos de design, moda, arte/educação e mais recentemente da inovação ${ }^{1}$ circunscrevem e que possam contribuir para que esses jovens estudantes de medicina possam compreender as relações de poder e distinção (BOURDDIEU, 1979) que o consumo dessas imagens midiáticas, altamente preparadas para a emulação de realidades, possam gerar, aqui destaca-se o acirramento de ações preconceituosas e de baixa tolerância com as discrepâncias sociais do nordeste brasileiro.

A finalidade aqui exposta fora a de proporcionar para esses alunos que eles pudessem entender, produzir e fazer circular novos significados (LOPES, 2015), novas produções e dotações de sentido (PIERCE, 1975) que colaborassem para a sua dimensão emancipatória com base nas dinâmicas de inclusão sócia, cultural e política e de combate aos discursos de ódio que veem sendo tão frequentes no campo da saúde.

1 Em 2017, com a inserção de conteúdos de design e moda para o primeiro ano da medicina observou-se a necessidade de sistematizar a 'vontade de inovação' - a partir do conceito de Foucault de 'vontade de verdade' - para a materialização, produção de conhecimento e formação com base no acompanhamento das vanguardas, tendências e vigências do design e da moda. 
Outro ponto de inferência que adensou a importância do LabFOL como parceiro formativo do curso de medicina é a provocação de um certo amadurecimento epistemológico na própria área do design e da moda, promovendo assim estudos de significação com base na semiótica (PEIRCE; DARRAS), semiológica (BARTHES) e discurso 'narrativa e visual' e (FOUCAULT; LOPES) e de Design e Arte/Educação (BARBOSA).

Com essa troca, teve-se a finalidade de colaborar com a organização de uma massa de estudos críticos que favoreça a alunos e profissionais que seja capaz de articular discussões cujo fundamento seja para a promoção do entendimento do campo das visualidades como um espaço humanista e para a emancipação (Boaventura de Souza Santos) das pessoas.

Fundamentadas as bases epistemológicas da parceria formativa entre os dois laboratórios, fez-se então necessário a construção de um corpo metodológico que abrigasse os saberes do campo das visualidades, mas que tivesse sentido para os alunos da medicina, e que colaborasse com sua formação.

Para isso, foi escolhida a metáfora formativa da "Equalização dos Distanciamentos Visuais", que visou articular o equilíbrio de forças estéticas entre a cultura visual acadêmica formativa da saúde e a célere produção de imagens cuja base é cultura de consumo global, por exemplo, nas redes sociais. Item que será discutido seguir.

\section{ENSINAR E APRENDER A MEDICINA COM DESIGN E MODA}

A metodologia adotada foi de base dialógica, e teve como principal fundamento provocar o que fora chamado de uma disposição para a "Equalização dos Distanciamentos Visuais", que significou por em discussão os valores provenientes dos alunos, notadamente os que geravam dinâmicas de distinção e poder em discussão, para que eles pudessem em grupo e individualmente compreender o quanto existe deles e o quanto existe de signos da cultura de consumo global e globalizante na paisagem visual que por eles era compreendida por "Estudar Medicina" ou "Ser Médico".

Como abordagem pedagógica para as dimensões teórica e prática, optou-se por se estruturar as aulas por meio da abordagem triangular de Ana Mae Barbosa, engendrando as ações de ver, contextualizar e fazer - do campo da arte/educação para os contexto formativo já determinado pelo Laboratório de Sensibilidades, em consonância com a adaptação para a análise do discurso visual dos Círculos de Cultura do pedagogo Paulo Freire -, adotando assim a cultura visual e gráfica como fonte dos argumentos informativos e formadores dos olhar.

A imagem abaixo visa esclarecer melhor os argumentos acima apresentados: 
Figura 02: A abordagem triangular e o ensino da medicina com base na perspectiva do Laboratório de Sensibilidades - UFPE - CAA.

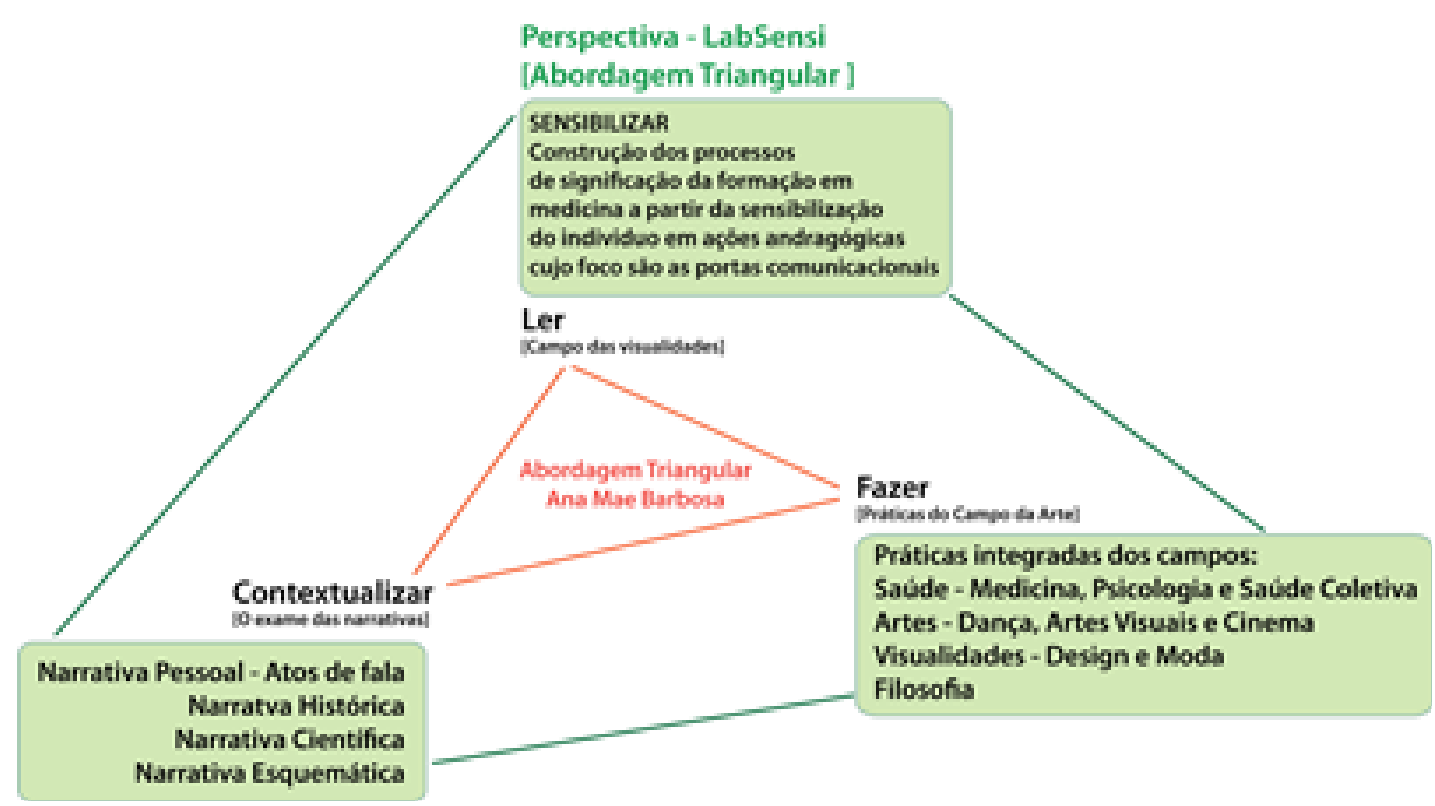

Fonte: Autora com colaboração de Eline Gomes e Heloisa Germany.

Esse esquema permitiu o entendimento de que era preciso organizar uma dinâmica de ensino e aprendizagem trifásica, que permitisse ao aluno da medicina as três experiências enunciadas por Ana Mae Barbosa. O Ler foi transposto para a leitura das paisagens visuais, imagens essas retiradas de redes sociais como o instagram, das séries de TV norte-americanas como em Grey's Anatomy ou Doctor House, cujo o processo de avaliação do sensível se deu por meio da semiótica peirceana, para poder se discutir, por exemplo, acolhimento da vulnerabilidade do aluno da medicina e do outro, no caso os futuros pacientes;

Já a dinâmica do Contextualizar foi feita pela discussão em sala de aula, mediada por atividades de observação de imagens, leitura de paisagens visuais que eles identificavam e altercação das suas projeções em desejos, em imaginário tanto de ordem pessoal quanto coletiva em grupos de alunos.

E o Fazer ficou entendido como a produção de artefatos em colaboração com os alunos de design que deram um suporte na parte de projeto e diagramação, para que seus posters pudessem exprimir o que eles aprenderam.

Essa relação de intercambiar design, moda e medicina foi assim desenvolvida, também em parceria com a professora Amanda Soares, que colaborou para a realização de uma série de pôsteres que tiveram como objetivo o aprendizado da relação prática que o design permite (projetar e diagramar), onde os alunos de medicina puderam projetar um pôster que demonstrasse a explicação de um sistema do corpo humano, como o nervoso, o circulatório, o reprodutor e/ou o digestório por meio de uma metáfora.

As metáforas escolhidas em parceria com a professora Amanda Soares 'aziam um paralelo com as redes de distribuição e de comunicação que estruturam a vida de uma cidade, como as redes de energia elétrica (sistema nervoso), as redes sociais (sistema reprodutor), as água e saneamento (sistema digestório), e a de distribuição de alimentos (Sistema circulatório), onde alguns resultados se pode ver a seguir: 
Figura 03: Posters de algumas equipes.

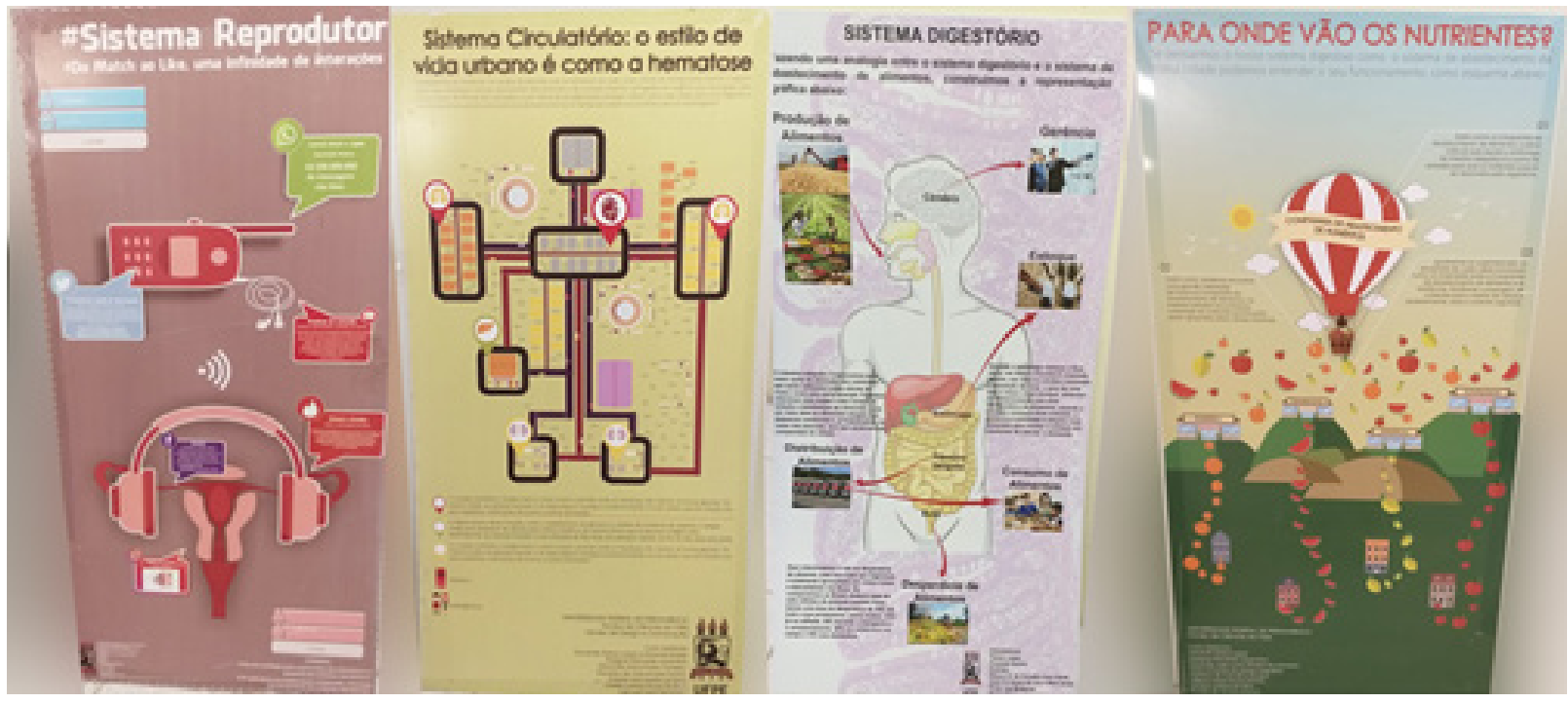

Fonte: Autora.

Essa atividade os alunos tiveram um grande prazer em fazer, em pensar como representar graficamente, para que público eles iriam apresentar e como eles iriam apresentar esse projeto. Ainda é importante destacar que, o tereceiro trabalho, da esquerda para direita, foi totoalmente produzido pleos alunos da medicina, incluso sua diagramação em softewares gráficos, já os demais contaram com a colaboração de alunos do curso de design também do CAA, uma parceria muito importante que proporcionou qualidade visual para os posters apresentados.

Para fundamentar essa proposta de ensino diante do campo da saúde foram utilizados dois documentos: As Diretrizes curriculares nacionais da graduação em medicina (DCN 14), que prevê no seu texto que a formação do aluno de medicina deve priorizar o estabelecimento de um relação profissional e ética. O outro documento utilizado foi o REVALIDA da Medicina, que informa que dentre as competências gerais estão o apoio à tomada de decisões e a compreensão de comunicação visual. E como competências específicas: a comunicação adequada, a saúde como direito, a crítica ao mercado de trabalho e análise do papel do médico na sociedade, princípios esses que foram estruturantes para o recorte do conteúdo formador no campo das visualidades.

Assim, de acordo com esse corpo de premissas, foram traçadas atividades de aulas expositivas com material e infografia apropriados cujas discussões pudessem elucidar dinâmicas como a significação dos objetos para ambos os campos (medicina e design), por meio de leituras imagética dirigidas à discussão em sala de aula, atividades de campo na comunidade-território como a de coolhunter, entendo-a como um processo de observação participante e por fim, atividades de análise do discurso textual e visual encontrado na rua e de produção de artefatos em colaboração com os alunos de design.

Um exemplo de uma discussão que os alunos vieram a achar muito interessante é a do Jaleco e do Estetoscópio e os seus múltiplos significados, a partir de uma analise de discurso visual pautada na experiência deles, e nos conteúdos de moda e de design, expressas nas imagens abaixo: 
Figura 04: Análise do sistema de significação de um Estetoscópio como artefato produzido pelo campo do design e utilizado pelo campo da saúde.

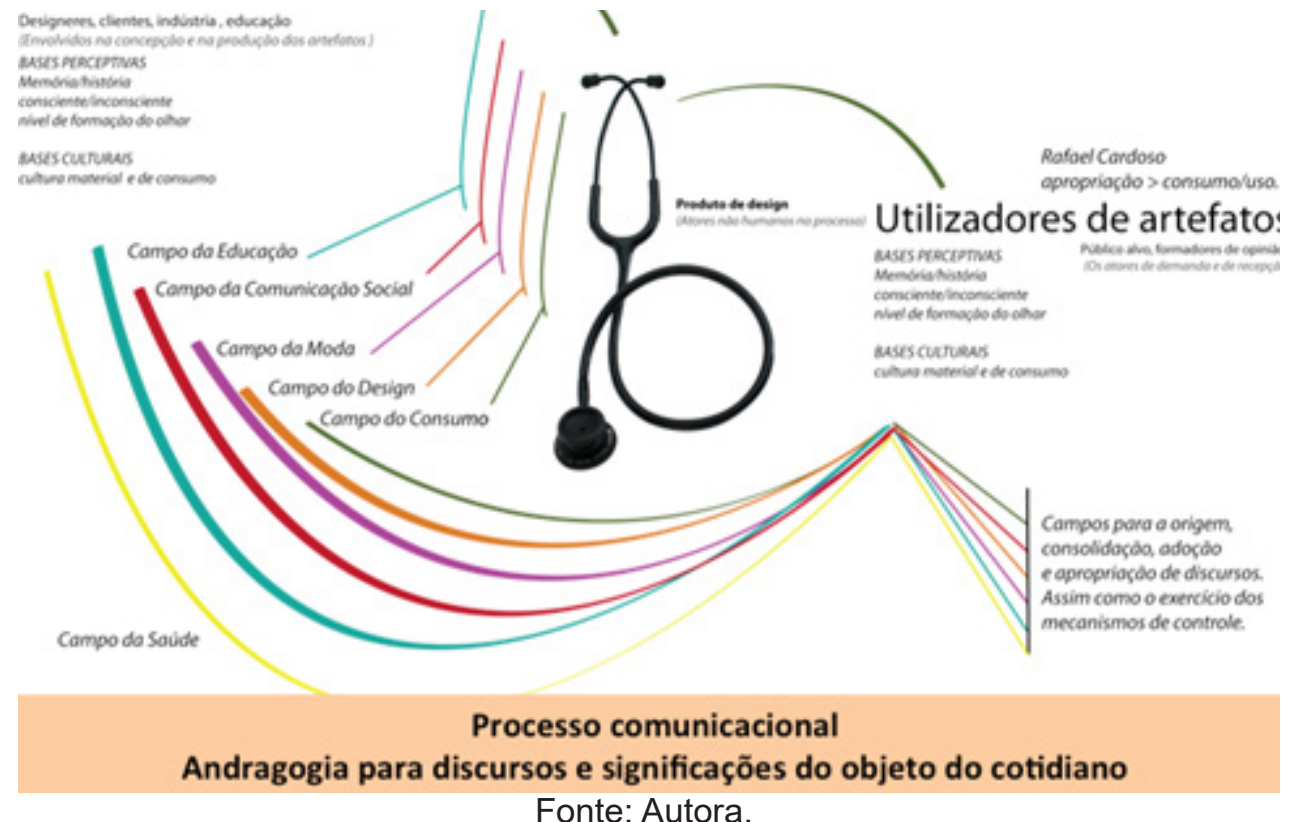

Esse gráfico ajudou aos alunos na copreensão de que existem várias intencionalidades, o que a Rafael Cardoso (1998), enterá como um processo de fetichisação, na produção dos objetos que fazem parte do cotidiano profissional deles, e que designers e consumidores são responsáveis por isso. Não há uma aleatoreidade nessa produção, pois ela também faz parte da cultura de consumo global.

Um outro ponto discutido a partir dessa imagem, foi o fato de que os objetos comuns em nossa vida podem ser utlizados como artefatos mediadores das relações de ensino e aprendisagem, de discussões onde podemos questionar nossos denodos, pois sua produção de sentido é feita pela interlocução de distintas camadas discursivas e também, por conta das tantas correntes de significação aos quais eles dão caminho as vivências do cotidiano.

Figura 05: Diversos estetoscópios com seus discursos visuais que atendem, cada uma, a uma demanda que os alunos puderam analisar segundo as suas vivências.

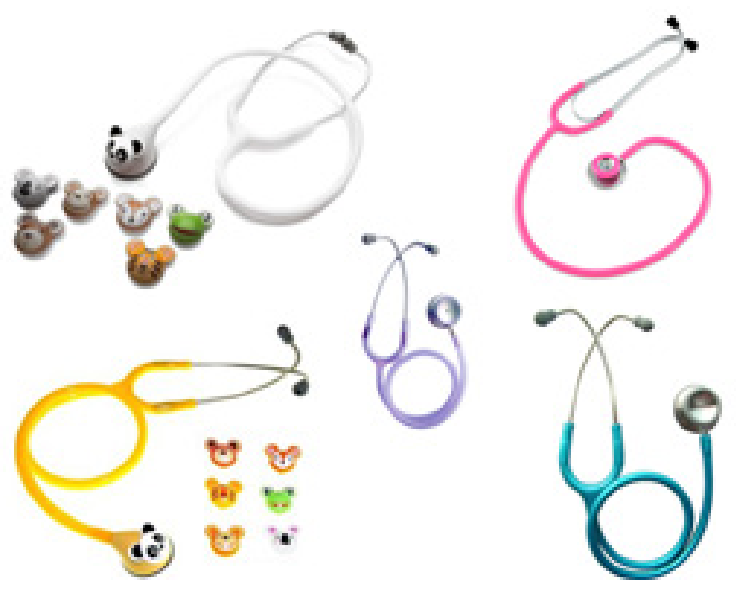

Fonte: Acessado na internet em maio de 2016.

A imagem acima veio para evitar que a discussão descambasse para a fetichização, como um ato banal, supérfluo do estímulo do consumo pelo consumo, mostrando que cores diversas e/ou as imagens de bichinhos, podem ajudar o profissional de 
saúde a se aproximar, por exemplo, de públicos como as crianças, que quando veem ao encontro de um profissional de saúde, muitas vezes estão fragilizadas, vulneráveis e a interface lúdica gera aí uma possibilidade de uma qualidade melhor na aproximação.

Figura 06: Análise do Sistema de Significação de um Jaleco como artefato produzido pelo campo do design e utilizado pelo campo da saúde.

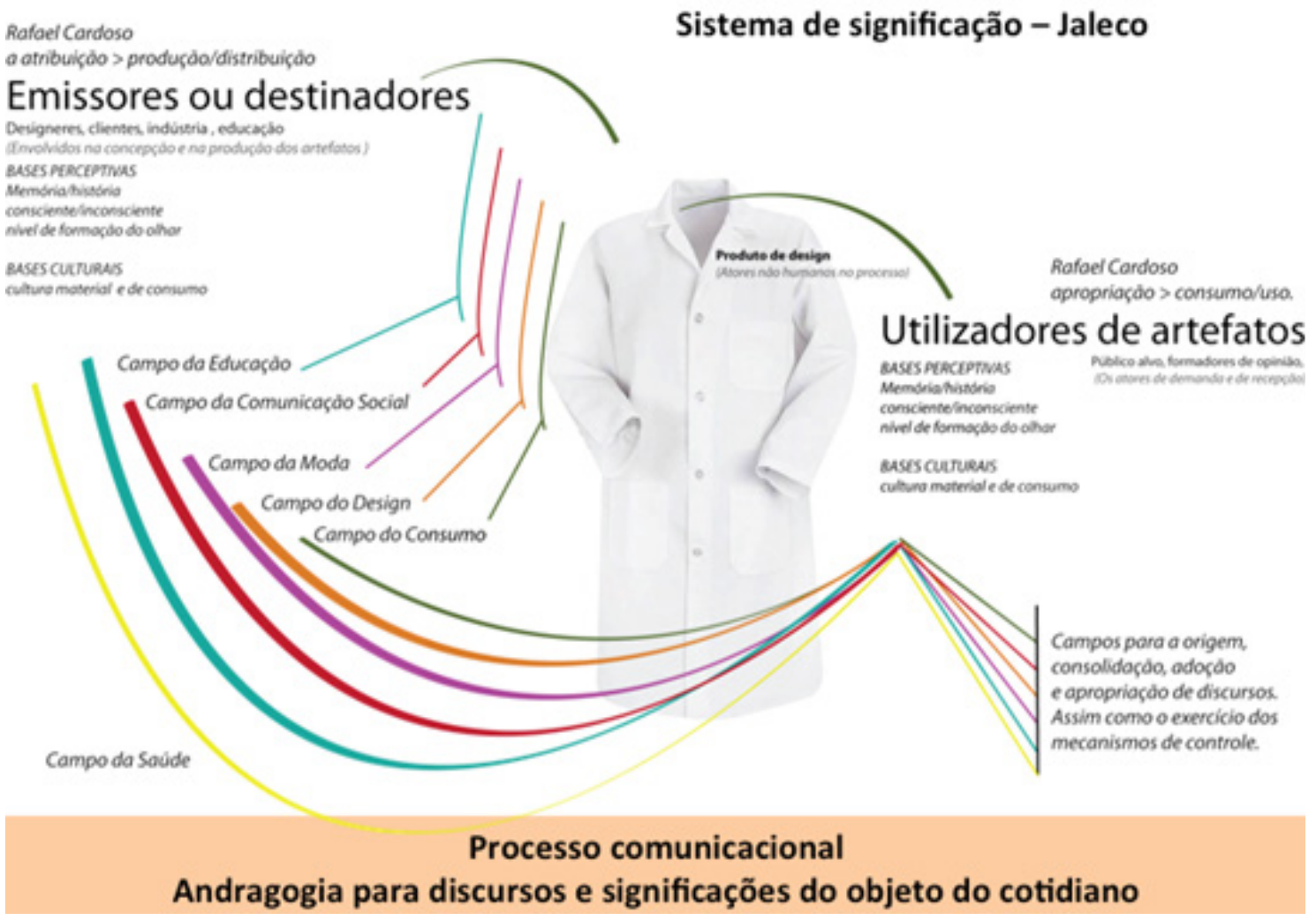

Fonte: Autora.

Assim, se pode entender tamém as dinâmicas de que as Bases Perceptivas de cada grupo: emissores e receptores de informações visuais, precisam ser discutidas para que haja o entendimento de que existe uma semiosfera (LOTYMAN, 1996) em comum, ou seja, de que é importante que as diversas camadas de signficação desses objetos sejam compreessíveis tanto para quem produz o objeto, quanto para quem recebe esse objeto em seu cotidiano.

Figura 07: Diversos estetoscópios com seus discursos visuais que atendem diversas dinâmicas como a inspiração em Pierre Cardin, Burberry e Romero Brito.
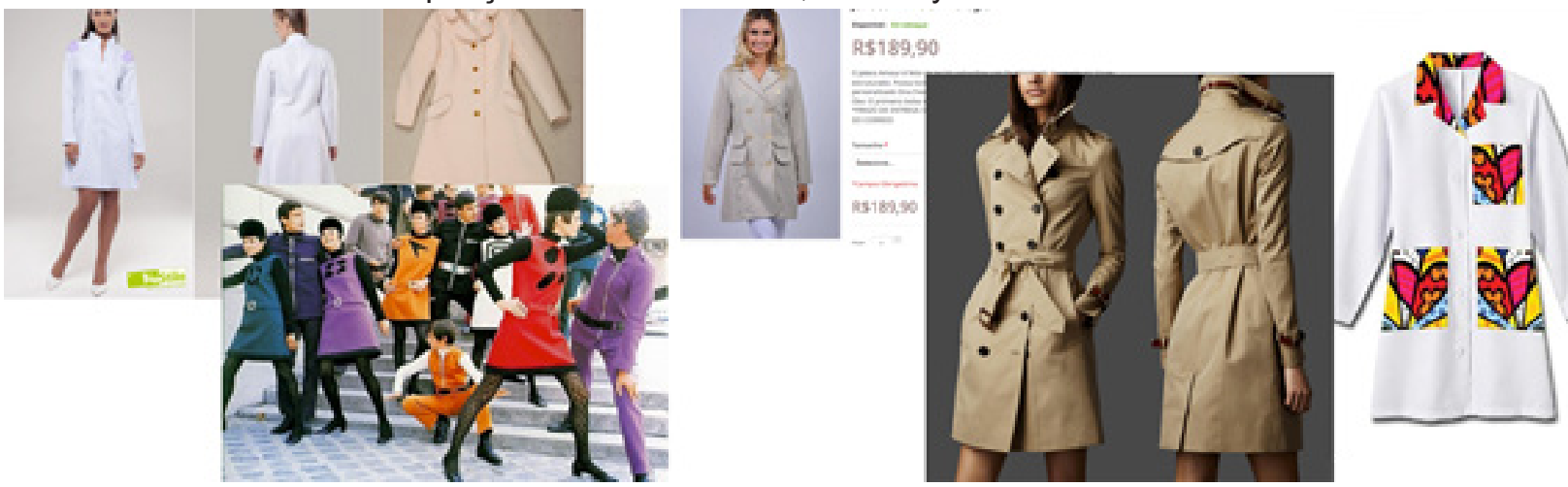

Fonte: Acessado de diversos sites em maio de 2016. 
Com essas imagens, todas elas amplamente discutidas em sala de aula, pode-se entende-las como possíveis elementos componentes da paisagem visual dos estudantes da medicina, e como um reflexo de absorção, para ampliação do consumo, da área da saúde, das influências dos estilos e da estética, por exemplo, dos anos 1960 com Pierre Cardin, ou a da cultura de consumo atual, com Trench Coat da Burberry, ou mesmo do campo das artes visuais, como a massificada proposta do artista Romero Britto.

Dessa forma, os alunos da medicina puderam intercambiar conteúdos e assim, entender que a relação estética é somente o início de um sistema de distinções e de relações sociais, mas que acaba também por ser muito importante por que desde o começo os valores sócio culturais de uma aparência, cuja intencionalidade é estruturada pelo design, muitas vezes precisa ser compreendida, para que de fato haja uma troca de significados e não somente o exercício da distinção entre os corpos.

Por fim, foi possível criar para esse aluno de medicina um entendimento geral de que em certas vivências culturais e até mesmo políticas e sociais, a moda, o design e a medicina acabam por ser um grupo de conhecimentos complementares, notadamente, quando, em sala de aula, o que é trabalhado são os sistemas distinções culturais, econômicas de classe social, de gênero, e destacadamente, as que existem numa região tão árida e carente de desenvolvimento quanto é o Agreste Pernambucano.

A partir da construção conjunta de que os espaços de conivência e os corpos das pessoas, seja ele o de uma mulher, ou de uma criança ou de um homem em vulnerabilidade, podem ser lidos, e compreendidos como um complexo sistema de materialização em aparência dos múltiplos discursos (narrativos e visuais), e são também consequências de uma dada época, do espírito do seu tempo e da sua condição social.

\section{ARREMATES E ENTENDIMENTOS FINAIS DO PROCESSO DE APRENDI- ZAGEM}

Pode se concluir então considerando que o processo de intervenção educacional narrado, que partiu do campo das visualidades, tomando o design e a moda como conteúdos interventores e interviu educativamente no curso de medicina, gerou um resultado satisfatório na medida em que os alunos puderam experienciar um pouco do pensamento de design em quanto espaço de poder e distinção e como atividade projetual e a moda como um argumento para a constituição da aparência das pessoas.

Assim, os alunos puderam compreender que projetar é um conhecimento que na contemporaneidade se faz presente, incluindo o campo da saúde, que a aparência é um local sócio-cultural e que faz parte da formação do olhar do médico entender esse sistema de signos e por fim, atualizar o seu olhar para as novas fronteiras que se abrem com essa intervenção.

Espera-se que o LabFOL tenha contribuído para os alunos se tornarem médicos cujo perfil profissional seja ampliado até o ponto em que eles também se estruturem não somente como consumidores de informações visuais, mas também como produtores, como uma massa crítica que são. E que assim possam colaborar com a sua comunidade acadêmica, na medida em que entendam-se como responsáveis para o desenvolvimento de um campo, cujos valores sejam mais sensíveis aos fenômenos que o campo das visualidades engendra, notadamente, nas realidades brasileira e agrestina. 


\section{REFERÊNCIAS}

BARTHES, Roland. Sistema da moda. São Paulo: Companhia Editora Nacional - USP, 1979.

BOAVENTURA, de Sousa Santos. A construção multicultural da igualdade e da diferença. Oficina do CES. N 135, Janeiro de 1999.

BARBOSA, Ana Mae. Teoria e Prática da Educação Artística. São Paulo: Cultrix, 1975.

BOURDIEU, Pierre. La distinction: critique sociale du jugement. Paris: Ed. de Minuit, 1979.

BRASIL. LEI No 13.243, DE 11 DE JANEIRO DE 2016. Dispõe sobre estímulos ao desenvolvimento científico, à pesquisa, à capacitação científica e tecnológica e à inovação e altera a Lei no 10.973.

CARDOSO, Rafael. Design, cultura material e o fetichismo dos objetos. Revista Ar$\cos ($ ESDI/UERJ), Rio de Janeiro, v. 1, n. 1, p. 14-39, 1998.

DARRAS, Bernard. Ensaio de modelização geral das relações humanas com os artefatos Estudo semiótico e sistêmico das interações. Conferência para o Seminário de Pesquisa em design de Informação. UFPE: Recife, outubro/2012.

FOUCAULT, Michael. A ordem do discurso: aula inaugural no Collège de France, pronunciada em 2 de dezembro de 1970/ Michael Foucault. tradução Laura Fraga de Almeida Sampaio. - 23 edição São Paulo: Edições Loyola. 2013

FREIRE, Paulo. Pedagogia do Oprimido. São Paulo: Editora Paz e Terra - 29a edição, 1987.

LOPES, M.T. Uma formação do olhar: o design da informação como conteúdo formador dos professores das licenciaturas brasileiras. UFPE, Recife: 2014. Mimeo. P. 499.

LOPES, M. T. Design de moda e inovação: um novo olhar sobre as Potencialidades do pólo de confecção do agreste Pernambucano. Anais do $11^{\circ}$ colóquio de moda - $8^{a}$ edição internacional e $2^{\circ}$ congresso brasileiro de iniciação científica em design e moda, 2015.

LOPES, M.T. A formação do olhar, o design de moda e a história da moda como argumento para a emancipação feminina. Anais do Seminário Moda Documento, 2016 Curitiba - PR .

LOTMAN, luri. La semiosfera I. trad, de Desidério Navarro, Madrid: Ediciones Cátedra, 1996. 
MAFFESOLLI, Michel. No fundo das aparências. Petrópolis: Vozes, 1996

PEIRCE, Charles Sanders. Semiótica e Filosofia. Trad. de Octanny Silveira da Mota e Leônidas Hegenberg. São Paulo: Cultrix-EDUSP, 1975.

Recebido em: 05/10/2018 Aceito em: 12/12/2018

DOI: http://dx.doi.org/10.5965/25944630312019047 